\title{
CRIATIVIDADE E INOVAÇÃO NA ESCOLA DO SÉCULO XXI: UMA MUDANÇA DE PARADIGMAS
}

\author{
CREATIVIDAD E INNOVACIÓN EN LA ESCUELA DEL SIGLO XXI: UN \\ CAMBIO DE PARADIGMAS.
}

\section{CREATIVITY AND INNOVATION IN THE XXI CENTURY SCHOOL: A PARADIGM SHIFT.}

\author{
Kênia Paulino de Queiroz SOUZA ${ }^{1}$ \\ Maria José de PINHO ${ }^{2}$
}

Resumo: Este artigo objetiva dar a conhecer as principais concepções de criatividade e inovação na escola contemporânea, com o rompimento do paradigma conservador para uma educação emancipatória, e discutir essa ruptura, que opera uma mudança nas instituições educativas segundo as concepções e os referenciais teóricos sobre o criar e o inovar, na "visão de transformação". O estudo, de caráter bibliográfico, iniciou com a análise dos aportes teóricos no "Grupo de Pesquisa em Rede Internacional Investigando Escolas Criativas e Inovadoras", que levou à percepção de que a escola contemporânea, ao opor-se a um ensino conservador, que prioriza o trabalho individual e o saber fragmentado, pode ser definida como emancipatória, criativa e inovadora, pois possui a visão formadora e transformadora de seu fazer pedagógico e coletivo, e busca a interligação dos saberes e a produção do conhecimento. Valoriza os potenciais criativos, a natureza e o ser humano, visando ao bem individual, social e planetário, segundo princípios que partem da vida e para a vida.

Palavras-chave: Transições paradigmáticas. Criatividade educacional. Produção do conhecimento.

Resumen: Este artículo tiene el objetivo de dar a conocer las principales concepciones sobre creatividad e innovación en la escuela contemporánea, con la ruptura del paradigma conservador para una educación emancipadora, y discutir esa ruptura, que opera un cambio en las instituciones educacionales segundo las concepciones y los referenciales teóricos sobre el crear y el innovar, en la "visión de transformación". El estudio, de carácter bibliográfico, se inició con el análisis de los aportes teóricos en el "Grupo de Investigación en Red Internacional Investigando Escuelas Creativas e Innovadoras", que condujo a la percepción de que la escuela contemporánea, al oponerse a una enseñanza conservadora, que prioriza el trabajo individual y el saber

\footnotetext{
${ }^{1}$ Mestre em educação pela universidade federal do tocantins - uft. Membro do grupo de pesquisa em rede internacional investigando escolas criativas e inovadoras. Professora da educação básica e superior. Email: keniaqueiroz06@hotmail.com

${ }^{2}$ Professora doutora da universidade federal do tocantins e do programa de pós-graduação em letras e no programa de pós-graduação em educação. Membro da Rede Internacional de Escolas Criativas - RIEC. Email: mjpgon@mail.uft.edu.br
} 
fragmentado, puede ser definida como emancipadora, creativa e innovadora, pues posee la visión formadora y transformadora de su quehacer pedagógico y colectivo, y busca la interconexión de los saberes y la producción del conocimiento. Valoriza los potenciales creativos, la naturaleza y el ser humano, pretendiendo el bien individual, social y planetario, según principios que parten de la vida y para la vida.

Palabras clave: Transiciones paradigmáticas. Creatividad educacional. Producción del conocimiento.

\begin{abstract}
This article aims to make known the main concepts of creativity and innovation in contemporary school, with the breakup of the conservative paradigm for emancipatory education, and discuss this break, which operates a change in educational institutions according to the conceptions and theoretical references on the create and innovate, in "vision of transformation". The study, of bibliographical character, began with the analysis of the theoretical in the "International Network Research Group Investigating creative and innovative Schools", which led to the perception that the contemporary school, to oppose a conservative education, which prioritizes the individual work and fragmented knowledge, can be defined as emancipatory, creative and innovative, because it has the vision and transformative forming of your do and pedagogical collective, and search the interconnection of knowledge and the production of knowledge. The creative potential, nature and the human being are valued, aiming at the individual, social and planetary good, according to principles that depart from and for life.
\end{abstract}

Keywords: Paradigmatic transitions. Educational creativity. Production of knowledge.

\title{
Introdução
}

O criar e o inovar estão voltados para as diferentes situações e circunstâncias do meio que envolve o ser humano, a vida. A criatividade precede a concepção de inovar, pois falar de inovação requer partir do princípio de uma ideia criativa que será organizada e materializada em algo novo, podendo ser um produto, uma prática ou ações inovadoras. No que se refere a políticas públicas, desde a década de 70 do século XX são implementados diferentes tipos de projetos e ações nomeadas de "inovação educacional", objetivando atender o sistema educativo do País, o que requer estudar os fundamentos que amparam a criatividade e a inovação.

O Ministério da Educação (MEC), na busca de solucionar vários entraves e desafios da educação básica, tem procurado incentivar ações "inovadoras" dentro das escolas. Esse incentivo, mais especificamente a partir dos anos 2000, se efetivou em diferentes níveis de ensino, procurando atender às demandas e às reivindicações da 
sociedade civil organizada e às necessidades de mudanças, em função das exigências socioeducacionais (SUANNO; DITTRICH; MAURA, 2013).

A intencionalidade em investigar a criatividade e a inovação escolar parte dos estudos no "Grupo de Pesquisa em Rede Internacional Investigando Escolas Criativas e Inovadoras", que tem como objetivos verificar indícios de práticas inovadoras e criativas nas escolas públicas municipais, nos anos iniciais do Ensino Fundamental e identificar se essa inovação parte de uma visão transformadora educacional que tende a superar a fragmentação do conhecimento por meio da (re) criação do seu fazer pedagógico, das suas concepções, de seus valores e fundamentos, tendo um olhar global do contexto escolar.

Este artigo tem como objetivo conhecer as principais concepções de criatividade e inovação da escola contemporânea, ao romper com o paradigma conservador, em busca de uma educação emancipatória.

Para tanto, recorre-se à análise bibliográfica ampla sobre as teorias que norteiam o contexto escolar emancipatório, tomando por base estes principais autores: CUNHA (2006); MORAES (1997); NASCIMENTO (2013); SUANNO; DITTRICH; MAURA (2013); TORRE (2008). Estas obras trazem as concepções de mudanças paradigmáticas do ensino conservador para o emancipatório: no primeiro, predominam a linearidade e a reprodução do conhecimento, enquanto no ensino emancipatório ocorre o inverso valorizam-se a produção e a construção de novos caminhos, novos conhecimentos, de forma coletiva e mais humana. Este estudo proporciona, por meio da discussão sobre as teorias, a compreensão dos principais conceitos que fundamentam as práticas criativas e inovadoras no processo de ensino emancipatório.

A escola criativa contemporânea, na visão cultural de uma instituição que visa formar e transformar, procura, de acordo com Zwierewicz (2011), desenvolver e valorizar os potenciais criativos, as capacidades empreendedoras, a importância do desenvolvimento do ser humano - tanto para o seu interior quanto para o exterior - a partir do seu entorno, visando ao bem individual, social e planetário.

Nesse contexto ocorre a discussão sobre a transição do paradigma conservador para a educação emancipatória, de acordo com os aportes teóricos e as reflexões para aqueles que têm a pretensão de conhecer concepções de criatividade e inovação e percebem a necessidade de rever a sua prática como instituições educativas com "visão transformadora", pois, segundo Carneiro (2013), o ser humano tem dentro de si a 
capacidade formadora e consegue transformar a sua realidade de acordo com a sua percepção criadora.

\section{Criatividade e inovação no contexto educacional emancipatório}

A concepção do criar, independentemente de onde surja, traz uma entonação de algo diferente para o espaço e o tempo determinados, e pode até mesmo se traduzir em diferentes valores para a vida a partir de uma existência criativa. $\mathrm{O}$ ser humano precisa de sua imaginação, necessita refletir, sonhar e se expressar com naturalidade, sem pressão, com desprendimento e liberdade desmedida. O criar está além do simples fato de criar; Carneiro (2013, p. 136) afirma que “[...] criar transcende a ação de gerar, porque ninguém cria a partir do nada, já que a base para tal processo é a própria experiência”. Enquanto Carneiro recorre às vivências como ponto essencial para transcender a ação de gerar, Rajadell (2012, p. 108) fala da capacidade que o ser humano possui em seu interior para imaginar e criar; fala do local inspirador, do inédito, das percepções ao criado; afirma que "[...] a criatividade é a capacidade humana para gerar ideias ou conexões imaginativas em um determinado campo, com certo nível de originalidade e de aportação de valor".

Para Nascimento (2013, p. 90), o ser criativo precisa de liberdade e também associa o envolvimento de seu meio para expressar o que faz parte de seu contexto, pois “[...] a criatividade é o próprio exercício da liberdade de pensar, de agir, de ser, além dos padrões que adotamos. Ser criativo implica em uma atitude livre, a partir da qual se assume um papel de responsabilidade pela criação (criar+ação) de sua própria realidade".

Para tanto, a prática escolar incentivadora do desenvolvimento criativo é imprescindível, pois "[...] o ser humano tem uma tendência natural de exprimir para si e para o outro aquilo que pensa e o que sente e isso só será possível se a escola permitir, incentivando a prática da criatividade" (CARNEIRO, 2013, p. 135), possibilitando a socialização de inúmeras ações e necessidades de sua realidade. $\mathrm{O}$ ser humano tem no seu interior a capacidade encantadora de imaginação para realizar projeções em seu exterior. Ao se referir à criatividade a partir da subjetividade humana, direcionada à especificidade do professor, entende-se que é a superação da normalidade de forma 
aberta, sensível e reflexiva, ao expressar-se de seu interior ao exterior. Pode-se entender que a

[...] criatividade é uma característica intrinsecamente humana, porque só o homem é capaz de criar projetando seu mundo interior sobre o meio. [...] existem algumas características que indicam o ato criativo. São elas a originalidade, a flexibilidade, a produtividade, a elaboração, a análise, a síntese, a abertura mental, a comunicação, a sensibilidade para os problemas e a redefinição. (TRIGO, 1999 apud CARNEIRO, 2013, p. 137)

Nem todas as criações são consideradas criativas, pois um ato criativo requer algo que exprima certa sensibilidade em seu produto final, que tenha uma originalidade para a superação de expectativas, de adversidades ou simplesmente seja o fato de exprimir um sentimento ou um recriar. Segundo Carneiro (2013, p. 137), “[...] a criatividade consiste, entre outras coisas, em uma visão singular do mundo que se faz acompanhar da emoção e isso ajuda o ser humano a refletir sobre a realidade", entrelaçando uma visão única com o seu interior, sua maneira de perceber o outro, o mundo, em que considera, a partir de suas vivências e dos conhecimentos adquiridos, a possibilidade de criar. Ou seja, "[...] criar depende das experiências que vão se acumulando ao longo da vida humana, de suas relações e dissociações de modo que cada um possa expressar-se" (CARNEIRO, 2013, p. 139), sentir-se e valorizar a própria vida.

As criações são inspirações que partem do meio em que o ser humano vive. Carneiro (2013, p.139) explicita que "[...] todo inventor por mais original que seja é produto da sua época e de seu ambiente. A obra criadora é, portanto, um processo histórico e consecutivo, onde cada nova forma se apoia nas precedentes". O criador precisa vivenciar as suas emoções e percepções para expressar a sua criatividade.

Os três autores, Carneiro (2013) Nascimento (2013) e Rajadell (2012), conceituam criatividade de formas diferenciadas, e em alguns momentos se encontram: há afirmações em que concordam entre si que o criar precisa ir além do apresentado, deve ser algo novo, "[...] uma marca única, inconfundível e diferente" (CARNEIRO, 2013, p. 137), “[...] criar novas realidades” (NASCIMENTO, p. 90, 2013), ou seja, “[...] com um certo nível de originalidade" (RAJADELL, 2012, p. 108).

Com essa concepção comum do que seja criar e com a agregação de outras afirmações, em que os autores apresentam como sentir, ver, observar, valorizar, reconhecer, gerar e ser livre, é que falar de criatividade no âmbito escolar não é 
simplesmente referir a uma ideia ou a um único conceito e sim, também na escola (CARNEIRO, 2013, p.140), “[...] transcender o conhecimento de conteúdos, requer alguns passos interessantes que vão desde a curiosidade, a demonstração, a sensação, a incerteza, a lógica, a imaginação, a corporeidade e a conexão", pois “[...] produtos orvalhados de criatividades impactam, motivam o aluno, aproximam o aluno, transmitem bem-estar" (RAJADELL, 2012, p. 108). Por isso a importância de se pensar em uma escola que seja criativa, que tenha em seus objetivos visões formadoras e transformadoras e que pense além de si mesma. Nessa mesma percepção, para Torre (2009, p.68), “[...] as Escolas Criativas são aquelas que vão adiante do lugar de que partem, oferecem mais do que têm e ultrapassam o que delas se espera, reconhecem o melhor de cada um e crescem por dentro e por fora, buscando o bem-estar individual, social e planetário".

A escola a que a autora se refere tem como objetivo preparar o aluno para vida, contribuindo com uma educação que estimula a consciência e os valores humanos, que procura sair da monotonia, do previamente estabelecido e fugir à falta de estímulos, pois,

[...] com as ações do cotidiano e as escolhas diárias, ao longo do tempo vamos deixando de criar e isso ocorre principalmente na escola, quando a imposição de currículos desvinculados da realidade e a repetição de tarefas monótonas, desmotivam as crianças, prejudicando o processo de criatividade. (CARNEIRO, 2013, p. 138)

Nessa perspectiva, o ensino criativo visa ultrapassar as barreiras impostas interna e externamente, não expressa autoritarismo, busca coletivamente o desenvolvimento do progresso humano dentro de infinitas atuações de comunicação. Leva em consideração que cada pessoa tem a sua particularidade, seu potencial humano e a sua responsabilidade individual. Faz-se necessário saber viver em sociedade, ter consciência de grupo, pois em uma escola não há funcionalidade a partir de um ser único, por ser ela uma comunidade educativa e criativa.

O trabalho em equipe também resulta básico para a evolução da própria sociedade; nossa sociedade evolui porque se discute, se debate, se planeja ou se tomam decisões, em um torno social. A diversidade de opiniões, conhecimentos e experiências proporciona aportação e riqueza para a equipe; devemos aceitá-la como valor que fomenta a abertura das fronteiras do conhecimento. (RAJADELL, 2012, p. 128) 
Segundo Rajadell (2012, p. 130), o ensino de uma escola que visa ao seu desenvolvimento coletivo requer um fazer "[...] coletivo que possua um ar de neutralidade, tolerância e respeito a determinados temas, atividades e abertura a sugestões e críticas dos demais, embora sempre sob um ambiente positivo". Fala-se na neutralidade de estar inserido em um grupo que respeita o saber e a concepção do outro enquanto equipe, e não de ser propriamente neutro nas ações, pois essas, em muitos momentos, exigem certas modificações para que um grupo aprenda realmente a desenvolver o seu trabalho de forma coletiva.

Essas mudanças estão mais fortes na sociedade educativa em tempos contemporâneos, que têm vivenciado a criatividade a partir de processos de desconstrução e reconstrução, em que muitas vezes não se sabe que situações estão sendo vividas. Suanno (2013) afirma que as situações adversas são estimulações para aqueles que conseguem aproveitar as circunstâncias e as adversidades, trabalhando em prol de mudanças criativas para novas aprendizagens e transformação de uma realidade. Nesse processo, o autor afirma que

[...] as adversidades, se percebidas como oportunidades de crescimento, podem ser de um novo ciclo e carregar forças de renovação, criação e inovação. Em momento de crise, em situações de grandes conflitos, caso a postura do sujeito, ou instituição, seja de enfrentamento e criatividade, o que é elaborado, quase sempre, é inovador. (SUANNO, 2013, p. 31)

O autor traz em sua afirmação que o planejamento realizado com criatividade para que haja mudanças em determinadas situações problemas, de crise, tem a possibilidade de gerar algo inovador. Mas também se pode observar que há uma diferença entre o criar e o inovar, ao mesmo tempo em que um complementa o outro, pois

[...] todos podemos ser criativos porque podemos gerar ideias, sejam mais simples ou complexas; porém não devemos confundir criatividade com inovação, porque a inovação é a capacidade organizativa para transformar uma boa ideia em um produto, serviço ou processo, aos quais sempre deve se acrescentar o fator êxito, focalizado em função de cada cenário. (RAJADELL, 2012, p. 108)

O processo de criatividade e o de inovação se diferenciam; no entanto, se relacionam na concretização de um produto consideravelmente positivo. Ou seja, a criatividade precede a inovação, pois, após surgir uma ideia criativa, a inovação cumpre 
a função de transformá-la em algo concreto e desejável ao processo educativo. Suanno (2013, p. 31) afirma que "[...] criatividade e capacidade crítica aliadas, no dia a dia, são grandes diferenciais para o surgimento de ações inovadoras". Considerando a busca de soluções aos entraves diários educacionais, o processo inovador tem como constitutiva e essencial a própria criatividade (CUNHA, 2006). O ato de inovar parte da necessidade de mudança de uma situação problema e da vontade de alteração: “[...] no Brasil o termo inovação educacional relaciona-se à solução de problemáticas da educação" (SUANNO; DITTRICH; MAURA, 2013, p. 211), é considerado o ato original, não necessariamente de grande dimensão, mas inédito, sensível à percepção humana em um processo de mudanças - não propriamente a mudança em si, mas o processo de gerar uma ação inovadora na área educacional, pois

[...] a inovação se associa com a autonomia quando entendida como ruptura paradigmática, na medida em que assume as relações que abandonam a verticalidade autoritária. [...] "A inovação se associa também com o novo, trazendo, nessa expressão, uma questão qualitativa, que envolve a introdução de algo ainda não estreado, não visto antes pelos alunos" (BROILO; PEDROSO; FRAGA, 2006, p.119).

Esse associar aqui referido não diz respeito a tudo o que seja inédito, pois nem tudo que é novo é inovador. Os autores prosseguem explicitando que o inédito “[...] existe em determinado lugar, tempo e circunstância, como produto de uma ação de pessoas sobre o ambiente ou meio social" (SUANNO; DITTRICH; MAURA, 2013, p. 211).

\section{A inovação educacional na mudança paradigmática}

Muitos entendem que inovar pode significar mudança para um produto consideravelmente melhor que o anterior, principalmente quando se refere à originalidade na escola. Às vezes, trata-se apenas de uma mudança de hábitos, mas traduz popularmente "inovação". $\mathrm{Na}$ sociedade contemporânea, as mudanças metodológicas ou curriculares podem ser inovadoras, mas também são autolimitadas no tempo e no espaço, e a sua abrangência no contexto educacional pode ser “[...] uma instituição, um curso, uma disciplina, ou referir-se a um método de ensino, a uma técnica, a um material, à avaliação, à atitude pedagógica" (SUANNO; DITTRICH; MAURA, 2013, p. 213 e p. 212). 
A concepção de inovação a partir de uma necessidade de ruptura é apresentada em relação à transformação do conhecimento sugerido:

[...] a inovação requer uma ruptura necessária que permita reconfigurar o conhecimento para além das regularidades propostas pela modernidade. Ela pressupõe, pois, uma ruptura paradigmática e não a inclusão de novidades, inclusive as tecnológicas. Nesse sentido envolve uma mudança na forma de entender o conhecimento. (CUNHA, 2006, p. 40-41)

A autora traz o conceito de inovação, apresentando como eixo principal a mudança, não a exclusividade do novo, como é citado nas tecnologias. No entanto, a inovação requer algo mais; a mudança do normal, das linearidades, para receber novas possibilidades de conhecer, transcender as regularidades e produzir novos conhecimentos, novas fronteiras.

Entendendo um pouco mais sobre a inserção da inovação, percebe-se que ela ultrapassa os muros escolares: inovar faz parte do todo educacional. Considerando que a inovação faz parte de um processo de mudanças a partir de situações conflitos, no Brasil, também a ação inovadora está entrelaçada na história da educação brasileira, desde o seu início, e perpassa a atualidade educativa, pois

[...] a inovação é o resultado de tensões de movimentos políticos que marcam a história do país e aqui se inclui a influência das relações internacionais, as quais estabelecem avanços e recuos na construção do projeto educacional, dependente das estruturas de poder dominante e, não, da simples inserção do novo ou da novidade. (CUNHA, 2002 apud SUANNO; DITTRICH; MAURA, 2013, p. 214)

Os movimentos políticos interferem no processo educativo, provocando grandes mudanças, mas a mudança não constitui a própria inovação em si, pois ela é indicativa de que os processos históricos, políticos e sociais têm influência em uma instituição educativa e na sociedade. A inovação parte de um determinado clima que, em muitos momentos, sinaliza a necessidade de modificações. Portanto, ela “[...] existe em determinado lugar, tempo e circunstância, como produto de uma ação de pessoas sobre o ambiente ou meio social" (CUNHA, 2006, p. 41), transformando diferentes circunstâncias. O inovar não é restrito a uma área específica, ou a uma dimensão educacional:

As inovações podem ser consideradas pedagógicas ou institucionais, pequenas ou grandes, impostas ou por adesão, entretanto a mudança continua a ocupar lugar de destaque no debate sobre inovação 
educacional, apesar de inovação e mudança não serem categorias equivalentes. Tem sido praxe a mudança constituir a preocupação da área socioeducacional, e a inovação, do campo da produção, da tecnologia e da administração. (SUANNO; DITTRICH; MAURA, 2013, p. 212)

Não há um campo específico e nem mesmo se parte de um procedimento determinado, para acontecer o processo inovador. As inovações estão em toda parte, a partir do olhar diferenciado na percepção provável entre o antes e o depois em uma instituição ou em quaisquer situações. As mudanças não são sinônimas de inovações, mas elas fazem parte de todo o processo e

[...] podem impulsionar mudanças significativas na aprendizagem docente. Elas se contrapõem a um modelo fechado e único de ensinaraprender e inter-relacionam-se, dinamicamente, a elementos internos e externos da instituição, e entendemos, aqui, a docência como atividade contextualizada e múltipla. (SUANNO; DITTRICH; MAURA, 2013, p. 217)

$\mathrm{O}$ ato de inovar na educação pode alterar tanto as políticas públicas quanto o fazer pedagógico, e não diz respeito exclusivamente ao interior de uma unidade de ensino, mas ele sobressai na sociedade, desde que exista um ser criativo com propósito de reorganizar uma ideia de forma a atender a sua realidade, a realidade social e comunitária. No momento em que esse ser criativo procura coletivamente desenvolver o seu trabalho de forma contrária a um determinado modelo de ensino, com objetivos voltados ao bem comum, consequentemente percebe-se "[...] que a inovação é tarefa de transgressores. Daqueles que estão convencidos de que a ordem habitual e rotineira do ensino deve ser alterada por novas formas [...] de compreender o mundo e exercer a docência" (CUNHA, 2006, p. 105-106), realizando uma mudança no processo educativo. E, na concretização desse processo de inovação educacional,

[...] para que as mudanças, nas práticas educativas, aconteçam é necessário que devamos interagir intencionalmente com os sujeitos e favorecer a interação entre eles, de forma a termos uma ação pautada numa nova concepção. As práticas inovadoras são possibilitadoras dessas ações porque se fundamentam na dimensão ontológica, epistemológica e metodológica do conhecimento. Tais práticas evidenciam que há necessidade de rompermos com o paradigma conservador e com a prática meramente transmissiva do saber com forte tradição no ensino[...] (SUANNO; DITTRICH; MAURA, 2013, p.225) 
Para entender esse rompimento, a mudança de paradigmas, Moraes (1997, p. 31) traz a concepção de que "[...] paradigma refere-se a modelo, padrões compartilhados que permitem a explicação de certos aspectos da realidade. É mais do que uma teoria; implica uma estrutura que gera novas teorias. É algo que estaria no início das teorias". $\mathrm{O}$ rompimento de um paradigma

[...] decorre da existência de um conjunto de problemas, cujas soluções já não se encontram no horizonte de determinado campo teórico, [...] inicia-se um processo de mudança conceitual, surge uma forma de pensamento totalmente diferente, uma transição de um modelo para outro, tudo isso decorrente da insatisfação com modelos predominantes de explicação. É o que se chama crise de paradigmas e que geralmente leva a uma mudança de paradigma. [...] surge um novo paradigma explicando os fenômenos que o antigo já não mais explicava. (MORAES, 1997 p. 55)

Para tanto, há necessidade de cuidar para não haver uma preocupação voltada simplesmente para o ato de rompimento em si ou para a introdução do novo, mas para pensar nas práticas inovadoras, que trazem "[...] a possibilidade de rompermos com o paradigma conservador em prol da perspectiva emancipatória" (SUANNO; DITTRICH; MAURA, 2013, p. 228), pois “[...] os processos de emancipações são estimuladores de intervenções compromissadas com as rupturas que atuam no sentido da mudança" (CUNHA, 2006, p. 17).

O romper com o conservador é andar na contramão de uma educação formadora e transformadora, que valoriza a produção do conhecimento, na concepção de que “[...] a razão de ser da educação é o gesto de formar pessoas na inteireza do ser, da formação do sujeito e da partilha com os outros, na construção livre e responsável de seu próprio mundo social, da profissionalização cotidiana, visando uma educação humanizadora" (SILVA, 2013, p. 146).

Uma educação que parte da vida e para a vida, valorizando o criar livre e inovador, enquanto o ensino tradicional prioriza a reprodução do saber, um ensino transmissivo, em oposição às mudanças, às inovações educacionais. Nesse sentido, considerando a importância da transição do paradigma conservador para o emancipatório, para um ensino voltado para práticas inovadoras formativas e transformativas, é preciso entender que a sociedade possui diferentes conceitos a respeito de inovação educacional: muitos entendem que apenas pensar em mudanças ou no novo possa conduzir à inovação ou à ruptura paradigmática. Mas 
[...] o uso de paradigmas deve ser entendido como sinalizador de movimentos que se aproximam em constante oscilação. A realidade é sempre multifacetada e precisa ser percebida como processo, como ato dinâmico e contextualizado. Grande parte das ações pedagógicas que procuram antecipar inovações, vivem intensos espaços na transição dos paradigmas, ora vivenciando práticas que façam avançar o modo tradicional, ora ainda reproduzindo processos presentes na história de cada um. O novo não se constrói sem o velho e é a situação de tensão e conflito que possibilita a mudança. (CUNHA, 2005, p. 24-25)

A inovação educacional não se limita ao período que corresponde à contemporaneidade, pois ela é construída como um processo que parte de algo existente: o conservador. No entanto, também diante das necessidades emergentes surgem as possibilidades de transformações, de um caminhar em oposição ao tradicional, para “[...] reformular a própria finalidade da educação, isto é, colocá-la a serviço das forças emergentes da sociedade" (SAVIANI, 1995, p. 24).

No intuito de se opor às desigualdades culturais e sociais, para atender a um paradigma emancipatório, é preciso um rompimento com o conservador. Essa ruptura (SUANNO; DITTRICH; MAURA, 2013, p. 219) “[...] não ocorre de forma linear e regular, uma vez que não existe um único sentido; é múltiplo e aberto, contraditório e complexo, o que possibilita um número infindo de interpretações e de compreensões".

A inovação parte de pretensões que visam sair do que está previamente estabelecido e ter a oportunidade de conhecer novas áreas de conhecimento, mudar o paradigma (CUNHA 2006). Também no que se refere à fragmentação do conhecimento, Suanno, Dittrich e Maura (2013, p. 224 - 225) afirmam que “[...] a realidade educacional não é vista como se fosse feita de racionalidade técnica e de fragmentação, mas, de processos que consideram o todo e, também, as partes, o conhecimento intuitivo, o emocional, o imaginativo e o sensível". Uma educação em que,

[...] ao se trabalhar conceitos e práticas transdisciplinares impõe-se uma atitude de compreensão da diversidade do modo de pensar. Olhar o outro desvela a cultura que nos forma, amplia horizontes e relativiza o que era tido como verdade única e indiscutível. Aceitar outros olhares como tendo o mesmo peso nos conscientiza dos mitos e do caráter particular de muitos valores que julgávamos universalistas, permitindo-nos descobrir o que realmente eles têm de universais. (SANTOS; SOMMERMAN, 2009, p. 93)

Com base nessa concepção, pode-se referir também ao ser educativo, que visa o global e não o saber fragmentado, o ser humano como um todo, um saber emancipatório, voltado ao exercício da cidadania, em que se percebe que o importante 
para "[...] um dos grandes aspectos de uma verdadeira Cidadania Planetária é exercer a responsabilidade de transformação social" (NASCIMENTO, 2013, p. 85) que se encontra no interior de cada um.

Nesse sentido, a transformação social por meio de práticas criativas e inovadoras no contexto escolar, que visa ao ensino emancipatório, vive o processo educativo pautado na visão do todo, procurando o fazer coletivo “[...] nos aspectos didáticos, metodológicos e curriculares, ou seja, na prática educativa em si" (NASCIMENTO, 2013, p. 75), vê o outro, o ser humano, inter-relacionado com a natureza, pois

[...] reaprender a contemplar a natureza, a ser sensível às suas necessidades e sabedorias, num caminho de reaproximação entre o ser humano e o natural é a característica mais importante de uma educação transdisciplinar, voltada à própria sobrevivência da nossa espécie e da vida tal qual como ela ainda se apresenta hoje em dia. (NASCIMENTO, 2013, p. 83)

O ser humano, na educação transdisciplinar, vê a natureza e a sua própria existência de maneira indissociável no planeta, no sentido de preservar sua sobrevivência, o que implica o cuidar para que a vida natural não morra, para uma educação que vise à superação da fragmentação, em que o ser humano seja parte de um todo, não viva isolado. As práticas educativas são diferenciadas, atendendo ao ser humano como um ser completo, valorizando todas as áreas de sua vida, pois

[...] a transdisciplinaridade maximiza a aprendizagem ao trabalhar com imagens e conceitos que mobilizam, conjuntamente, as dimensões mentais, emocionais e corporais, tecendo relações tanto horizontais como verticais do conhecimento. Ela cria situações de maior envolvimento dos alunos na construção de significados para si. (SANTOS; SOMMERMAN, 2009, p. 26)

Esta é a visão de uma educação transformadora que busca a interligação do conhecimento em sua prática educativa, de forma inovadora, global e formadora, antes fragmentada.

Nesse olhar emancipatório, a escola tem como objetivo principal a "[...] criação de novas possibilidades formativas”. Proporcionar às unidades de ensino as práticas educativas inovadoras para que, “[...] na medida em que os processos de busca de rompimento paradigmático se desenvolvem e se fortalecem coletivamente, cria-se, cada vez mais, a possibilidade de construção da autonomia” (FOSTER et al. 2006, p. 52). É importante que o sujeito tenha a autonomia para, como ser reflexivo, contribuir no processo criativo, não de forma individualizada, mas fortalecendo o coletivo e 
promovendo a associação da inovação com a autonomia, quando entendida como ruptura paradigmática, na medida em que assume as relações que abandonam a verticalidade autoritária (CUNHA, 2006).

Para que de fato uma escola possa ser inovadora, na transição do paradigma conservador para o paradigma emancipatório, se faz necessário que em sua prática educativa estejam incluídas ações voltadas para “[...] desenvolver nos alunos os atributos mais característicos da criatividade, tais como a originalidade, flexibilidade, elaboração, inventividade" (TORRE, 2008, p.83), a fim de que sejam preparados para interagir com o mundo crítico, e que se

[...] dê espaço para criatividade e para o erro, pois não há aprendizagem sem ele; ofereça espaço para o diálogo e para a emoção; crie situações que fortaleçam o respeito mútuo; evite dar respostas prontas; valorize a experiência de cada um; pense e replaneje em ação. (SANTOS, 2013, p. 130)

Nessa nova percepção é importante que, no processo de ensino e aprendizagem na escola criativa e inovadora, o aluno seja um dos protagonistas, que pense criticamente e tenha voz em seu processo educativo, pois assim ele será o autor de seus próprios conhecimentos. E também sejam os professores, no processo emancipatório, agentes que compõem a construção desse processo, que

[...] demanda uma atitude consciente, autônoma e intencional do docente em criar e descobrir um novo jeito de conceber o saber e o conhecer, em busca de novos sentidos que emergem das dinâmicas energéticas interpessoais que brotam dos ambientes educativos nos quais os sujeitos convivem. Os sujeitos nesses ambientes formam e transformam não somente a dimensão cognitiva do ser, mas o pensamento metacognitivo, os socioafetivos, culturais, a evolução da consciência, os diálogos, as trocas de experiências, o espírito criativo e as relações entre as diversas áreas do conhecimento que impulsionam e tornam possíveis outras inovações. (PINTO, 2011 apud SUANNO; DITTRICH; MAURA, 2013, p. 228)

Nessa nova forma de aprender e compreender que o criar e o inovar no contexto escolar contam com vários agentes indispensáveis nesse processo de ruptura paradigmática do conservador para o emancipatório, todos os integrantes são importantes para intervir com “[...] propostas pedagógicas que se voltem para a realidade atual" (ZWIEREWICZ, 2013, p. 173), que atendam ao ser, à sociedade, à natureza, à vida, em um processo que não tenha uma visão dicotômica do ensino, pois é “[...] necessário um novo pensar capaz de estabelecer relações, vital para se formar um 
todo, viável e visível tanto no nível global como no de cada ser humano em particular" (FURLANETTO, 2011, p. 126), capaz de buscar o processo de união, em vez de separar, em uma educação diferenciada na sua forma de pensar.

\section{Considerações finais}

Diante das análises bibliográficas, pode-se verificar que a inovação e a criatividade no contexto educativo partem do pressuposto de uma educação formadora e transformadora como ensino emancipatório, que tem por base partir da vida e para a vida, valorizando o ser humano como um ser completo em seu interior e integrante do planeta.

Busca-se, por meio da mudança paradigmática, a interligação do conhecimento, um princípio transdisciplinar, sem preconceitos e valorizando o ser humano como um todo. Uma educação com o predomínio das ações planejadas e executadas coletivamente, apreciando tanto o potencial criativo discente e docente quanto o da instituição, considerando toda a comunidade educativa.

Os fundamentos teóricos estão pautados na perspectiva de criatividade e inovação, a partir de um processo de mudança que busca a ruptura com a fragmentação do saber e das práticas pedagógicas e passa a reconhecer o global como importante.

A criatividade, em sua ação original de pensar, refletir de maneira livre, flexível, nova e consciente, a partir de sua realidade, de forma interligada com o processo inovador, busca organizar esse criar com certo êxito, no que se refere às práticas inovadoras em promover mudanças de um ensino transmissivo do saber para a produção do conhecimento, o que possibilita, tanto ao docente quanto ao discente, que sejam protagonistas de sua própria aprendizagem.

A escola criativa, neste novo paradigma que visa ao ensino formador e transformador, não tem como objetivo atender da forma que todas atendem, pois ela não tem como foco a ação mercadológica, não pensa só nas demandas de uma sociedade capitalista, mas prepara o aluno para a vida, desde o seu interior como um ser pensante, como um ser ativo no individual, com suas limitações, e no coletivo, com autonomia, na comunidade educativa e na sociedade geral.

Diante do exposto, a escola contemporânea pode ser definida como criativa e inovadora quando se dispõe a transformar o seu fazer pedagógico, coletivo, de forma 
consciente e emancipatória, atenta para si e para o seu entorno, como parte integrante da sociedade.

Esta nova forma de conceber o conhecimento busca, em sua prática educativa, a superação do ensino linear, uma busca constante em meio a situações complexas de um ensino em geral fechado, que dita normas e regularidades de cima para baixo. Busca suplantar uma educação permeada no ensino conservador, onde não há o compartilhar, nem o trabalho em equipe.

No entanto, em meio às adversidades, rumo à transformação, nesta sociedade contemporânea, há o crescimento de instituições com uma visão diferenciada desse ensino tradicional. Elas caminham cultivando mais a participação coletiva e o valor à vida, avançando em seu processo criativo e inovador, para de fato serem partícipes de uma educação emancipatória.

\section{REFERENCIAS}

BROILO, C. L.; PEDROSO, M. B.; FRAGA, E. T. Os alunos parceiros: adesões e resistências às inovações no espaço de sala de aula. In: CUNHA, M. I. da. (Org.). Pedagogia universitária: energias emancipatórias em tempos neoliberais. Araraquara: Junqueira \& Marin, 2006.

CARNEIRO, M. A. B. Criatividade: potencial a ser desenvolvido em profissionais da educação infantil. In: SUANNO, M. V. R.; DITTRICH, M. G.; MAURA, M. A. P. (Org.). Resiliência, criatividade e inovação: potencialidades transdisciplinares na educação. Goiânia: UEG; América, 2013.

CUNHA, M. I. da. O professor universitário na transição de paradigmas. 2. ed. Araraquara: Junqueira \& Marin, 2005..

CUNHA, M. I. da. (Org.). Pedagogia universitária: energias emancipatórias em tempos neoliberais. Araraquara: Junqueira \& Marin, 2006.

FOSTER, M. M. et al. Alguns caminhos para compreender o processo de construção da inovação. In: CUNHA, M. I. da. (Org.). Pedagogia universitária: energias emancipatórias em tempos neoliberais. Araraquara: Junqueira \& Marin, 2006.

FURLANETTO, E. C. Formação e transdisciplinaridade: o encontro com a experiência. In: TORRE, S. de la et al. Formação docente e pesquisa interdisciplinar - criar e inovar com outra consciência. Blumenau: Nova Letra, 2011. 
MORAES, M. C. O paradigma educacional emergente. 9. ed. Campinas, SP: Papirus, 1997.

NASCIMENTO, P. L. Parâmetros para análise-síntese de práticas educativas. In: SUANNO, M. V. R.; DITTRICH, M. G.; MAURA, M. A. P. (Org.) Resiliência, criatividade e inovação: potencialidades transdisciplinares na educação. Goiânia: UEG; América, 2013.

RAJADELL, N. A importância das estratégias didáticas em toda ação formativa. In: SUANNO, M. V. R.; PUIGGRÓS, N. R. (Org.). Didática e formação de professores: perspectivas e inovações. Goiânia: CEPED Publicações; PUC Goiás, 2012.

SANTOS, A.; SOMMERMAN, A. (Org.). Complexidade e transdisciplinaridade. Porto Alegre: Sulina, 2009.

SANTOS, E. C. dos. A prática criativa no ofício do professor. In: TORRE, S. de la et al. (Coord.). Inovando na sala de aula - instituições transformadoras. Blumenau: Nova Letra, 2013.

SAVIANI, D. A filosofia da educação e o problema da inovação em educação. In: GARCIA. W. E. (Coord.). Inovação educacional no Brasil: problemas e perspectivas. 3. ed. São Paulo, SP: Autores Associados, 1995.

SILVA, V. L. de S. e. Estágio na formação de professores no ensino superior: uma vivência transdisciplinar. In: TORRE, S. de la et al. (Coord.). Inovando na sala de aula - instituições transformadoras. Blumenau: Nova Letra, 2013.

SUANNO, J. H. Adversidade, resiliência e criatividade: uma articulação oportuna? In: SUANNO, M. V. R.; DITTRICH, M. G.; MAURA, M. A. P. (Org.). Resiliência, criatividade e inovação: potencialidades transdisciplinares na educação. Goiânia: UEG; América, 2013.

SUANNO, M. V. R.; DITTRICH, M. G.; MAURA, M. A. P. (Org.). Resiliência, criatividade e inovação: potencialidades transdisciplinares na educação. Goiânia: UEG; América, 2013.

TORRE, S. de la. Professor e alunos criativos. In: TORRE, S. de la. Criatividade aplicada: recursos para uma formação criativa. Tradução WIT Languagens. São Paulo: Madras, 2008.

TORRE, S. de la. Escolas criativas: escolas que aprendem, criam e inovam. In: ZWIEREWICZ, M.; TORRE, S. de la. (Coord.). Uma escola para o século XXI: escolas criativas e resiliência na educação. Florianópolis: Insular, 2009. p. 55-69.

ZWIEREWICZ, M. Formação docente transdisciplinar na metodologia dos projetos criativos ecoformadores - PCE. In: TORRE, S. de la et al. Formação docente e pesquisa interdisciplinar - criar e inovar com outra consciência. Blumenau: Nova Letra, 2011.

ZWIEREWICZ, M. Projetos criativos ecoformadores - PCE: uma via metodológica desde e para o paradigma da complexidade. In: TORRE, S. de la et al. (Coord.). Inovando na sala de aula - instituições transformadoras. Blumenau: Nova Letra, 2013. 


\section{Como referenciar este artigo}

SOUZA, Kênia Paulino de Queiroz.; PINHO, Maria José de. Criatividade e inovação na escola do século XXI: uma mudança de paradigma. Revista Ibero-Americana de Estudos em Educação, Araraquara, v. 11, n. 4, p. 1906-1923, 2016. Disponível em: <http://dx.doi.org/10.21723/riaee.v11.n4.6636>. E-ISSN: 1982-5587.

Submissão em: fevereiro/2014

Aprovação final em: agosto/2016 